\title{
CRESCIMENTO, LONGEVIDADE E RECRUTAMENTO JUVENIL DO CAMARÃO-BRANCO LITOPENAEUS SCHMITTI (BURKENROAD, 1936) (DECAPODA: PENAEOIDEA) NA REGIÃO SUDESTE DO BRASIL
}

\author{
Miazaki, L.F. ${ }^{1,}$; Santos, A.P.F. ${ }^{1}$; Simões, S.M. ${ }^{2}$ \& Costa, R.C. ${ }^{1}$ \\ ${ }^{1}$ Universidade Estadual Paulista (UNESP), Campus Bauru, \\ Laboratório de Biologia de Camarões Marinhos e de Água Doce. \\ ${ }^{2}$ Universidade Estatual Paulista (UNESP), Campus Jaboticabal \\ *Autor correspondente: lizandramiazaki@gmail.com
}

Litopenaeus schmitti é um dos peneídeos mais explorados comercialmente na costa Sudeste e Sul do Brasil. Desta forma, informações acerca do recrutamento juvenil e dos padrões de crescimento dos indivíduos são importantes para futuros programas de manejo. O presente estudo teve como objetivo estimar os parâmetros de crescimento, longevidade e recrutamento de L. schmitti na região de Ubatuba/SP. Para as estimativas dos parâmetros de crescimento, todas as coortes escolhidas foram ajustadas ao modelo de crescimento de von Bertalanffy (1938) dada por $\mathrm{CC}_{\mathrm{t}}=\mathrm{CC}_{\infty}\left[1-\mathrm{e}^{-\mathrm{k}(\mathrm{t}-\mathrm{t})}\right]$, onde: o comprimento da carapaça $\mathrm{CC}_{\mathrm{t}}$ é o tamanho estimado na idade t; $\mathrm{CC}_{\infty}$ é o tamanho assintótico; $\mathrm{k}$, o coeficiente de crescimento e $\mathrm{t}_{0}$ equivale à idade teórica que o organismo teria no tamanho igual a zero. Os parâmetros de crescimento foram estimados para as diferentes

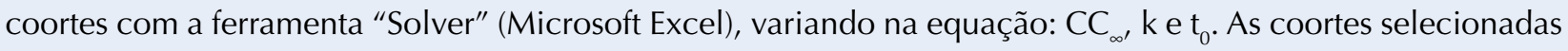
foram aquelas com um ritmo biológico coerente, no que diz respeito à longevidade, coeficiente de crescimento e tamanho assintótico $\left(\mathrm{CC}_{\infty}\right)$. A longevidade foi estimada por meio da equação inversa de von Bertalanffy. As coletas foram realizadas mensalmente, no período de julho de 2005 a junho de 2007 no estuário formado pelo rio Indaiá e na baía adjacente (Ubatuba). Foram amostrados 1277 indivíduos, sendo 598 fêmeas e 679 machos. Os parâmetros de crescimento estimados para fêmeas e machos foram, respectivamente: $\mathrm{CC}_{\infty}=53,10$ $\mathrm{mm}$ e 43,23 mm, $\mathrm{k}=1,82 /$ ano e 2,19/anos, $\mathrm{t}_{0}=1,10$ e 0,69, e longevidade de 2,27 e 2,10 anos. O dimorfismo sexual em relação ao tamanho é comum para as espécies da família Penaeidae e está relacionado ao maior volume do cefalotórax das fêmeas. Consequentemente, há uma maior produção de oócitos nesses camarões já que que a fecundação é externa. O recrutamento juvenil ocorreu sazonalmente entre dezembro e abril no primeiro ano de amostragem e de novembro a maio no segundo ano. Embora o principal pico de juvenis, na região estuarina em março/2007, tenha coincidido com o período de fechamento da pesca, a reabertura da pesca em junho, possivelmente, promove a captura de grandes quantidades de recém-adultos, que ainda não participaram da primeira reprodução.

Palavras-chave: pesca de camarão, período de defeso, von Bertalanffy, coeficiente de crescimento.

Financiamento: FAPESP \# 2004/07309-8; CAPES 88887.161311/2017-00. 